\title{
A timeline for the introduction of synthetic dyestuffs in Japan during the late Edo and Meiji periods
}

\author{
Anna Cesaratto ${ }^{1}$, Yan-Bing Luo ${ }^{2}$, Henry D. Smith $\|^{3}$ and Marco Leona ${ }^{1 *}$
}

\begin{abstract}
A widespread belief among scholars and connoisseurs of the Japanese color woodblock print (nishiki-e) holds that synthetic dyes were imported from the West in the 1860s, and soon came to be used for all nishiki-e colorants during the Meiji period. These "cheap imported aniline dyes" are widely described as "gaudy", "garish", and "strident", and thought to stand in sharp contrast to more muted "natural" colorants that preceded them. This study calls this narrative into question through an analysis of the colorants of nishiki-e from 1860 until 1900, using surface-enhanced Raman spectroscopy coupled with micro-Raman, XRF and fiber optic reflectance spectroscopies. The results show that the introduction of synthetic dyes was gradual and selective, and that most of the customary colorants of the late Edo period continued in use. The results revealed a series of key turning points after 1860: (1) In 1864, the purple dye rosaniline became the first synthetic dye to be used in nishiki-e, at first in combination with Prussian blue for a more bluish color. From 1875, it was usually mixed or replaced with methyl violet for a stronger purple. (2) In early 1869, a dramatic and until recently unrecognized transition took place, from the longstanding use of safflower as the dominant red, to its total replacement by imported cochineal carmine. Carmine remained the primary red for the next two decades, often combined with vermillion. (3) In 1877, eosine appeared as the first synthetic red dye in nishiki-e, used alone for pink, and in mixture with carmine for red. (4) Finally, from 1889, a succession of red naphthol dyes of more striking color appeared. Just about this time, however, a tendency to more restrained use of color and more painterly effects began to emerge in nishiki-e, and with the exception of a burst of dynamic color in prints depicting the SinoJapanese War (1894-95), the uses of strong colors in Meiji prints receded. A final key finding is that colorants were often combined, either through mixture in a bowl or on the printing block, or by two-step overprinting.
\end{abstract}

Keywords: Japanese woodblock prints, nishiki-e, ukiyo-e, Synthetic colorants, Aniline dyes, Eosin, Naphthol reds, Inks for chromolithography, Micro-Raman spectroscopy, SERS

\section{Introduction}

Descriptions of Japanese color woodblock prints (nishiki$e$ ) of the Meiji period (1869-1912) inevitably draw attention to their bright colors (as can be seen in Fig. 1), which are uniformly characterized as the result of new synthetic dyes imported from Europe. A recent reference work in English on Japanese woodblock prints describes "a new and unexplored palette" that arrived "from the early

\footnotetext{
*Correspondence: Marco.Leona@metmuseum.org

${ }^{1}$ Department of Scientific Research, The Metropolitan Museum of Art, 1000 Fifth Avenue, New York, NY 10028, USA

Full list of author information is available at the end of the article
}

1860 s" and was popular by the 1870 s, asserting that "with the 1880 s aniline dyes had practically replaced the older vegetable and mineral colourants". The dyes themselves are characterized as "imported aniline colours, including harsh yellows, greens, purples, and red, with red so prominent that they have also been labelled, somewhat pejoratively, aka-e ('red pictures') [1]".

Meanwhile, a leading contemporary Japanese scholar of ukiyo-e describes a new aniline red in Meiji prints as "a garish (dogitsui) red that by today's standards could never be considered tasteful, but it... became a trendy sign of a new era, suddenly becoming a dominant color that worked to paralyze the color sensibilities of the people 


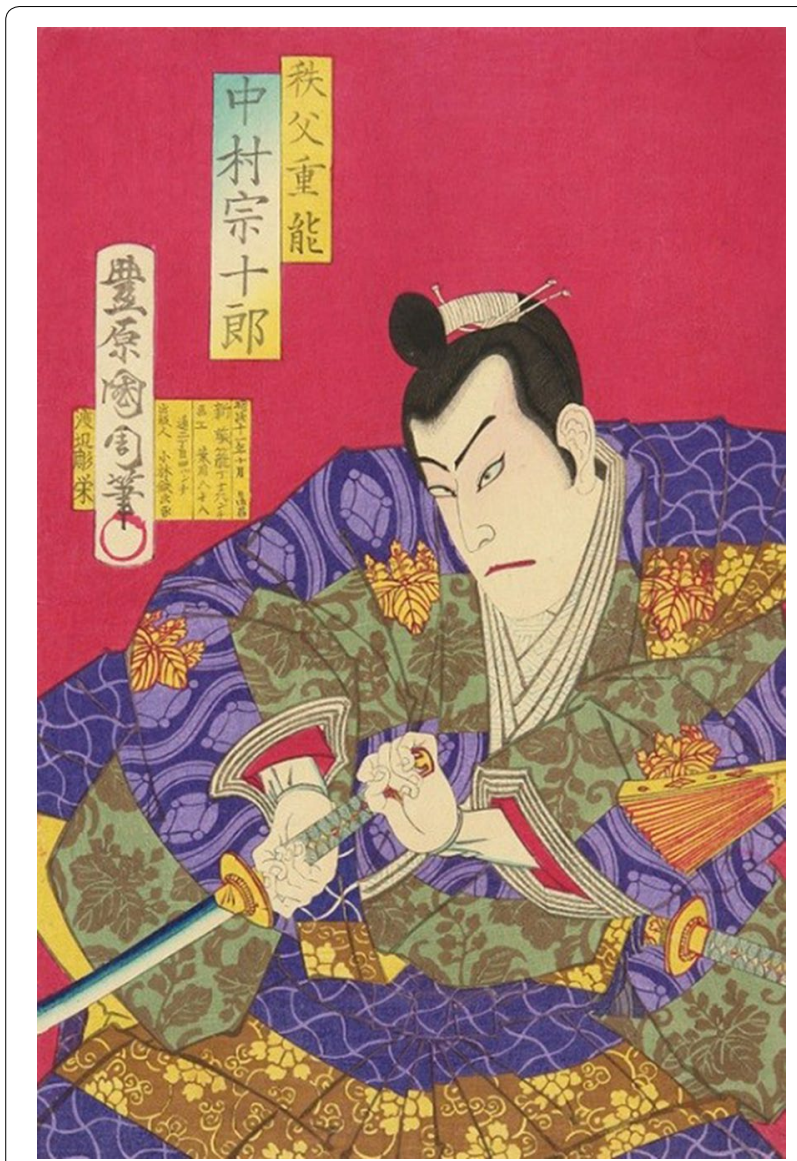

Fig. 1 Japanese woodblock print realized by Kunichika in October 1878. Red and purple colors are the protagonists of the scene

[2]". Although some have assessed these new colors in a more positive light, such as Meech's description of "vibrant colors eminently suited to the bright sunshine of Meiji enlightenment" [3] most writings on ukiyo-e in both Japanese and English continue to depict a wholesale replacement in the 1860 s of older vegetable dyes with new synthetic colorants.

This study aims at tracking the introduction of synthetic colorants into Japan through the scientific analysis of a sample of nishiki-e woodblock prints covering most years from the 1860s through the 1890s. The high rates of survival, good preservation, and exact dating make these prints ideal candidates for our purposes. This makes it possible to establish a reliable timeline for the introduction of new colorants, and to enable a scientifically and historically informed reconsideration of the ways in which they have been characterized in the past.

\section{Methods}

\section{The woodblock prints}

A collection of 57 woodblock prints was assembled by Henry D. Smith II specifically for this study, on the basis of date of publication. The collection covers the time period from the opening of the port of Yokohama to international trade in 1859 , until 1898 when the color woodblock medium was in decline. Four prints belonging to the Metropolitan Museum of Art collection (JP3277, JP3259, JP3272, JP3233, dating respectively to September 1877, May 1881, May 1887 and March 1889) were also included in the study. All of the prints in this study can be dated with precision to year and often to the month of issue, allowing us to trace with accuracy the use and introduction of European dyestuffs.

The complete list of prints in the collection can be find in Additional file 1: Table S1.

\section{Reference dyestuffs}

Safflower red was obtained by alkaline extraction $(0.1 \mathrm{M}$ $\mathrm{KCO}_{3}$ water solution) from a cotton fabric dyed with the dried petals of the flower. Carmine was obtained from the swatches of an early twentieth century Winsor and Newton catalogue, previously analysed by HPLC and surfaceenhanced Raman spectroscopy to confirm the identity of the colorant. Eosin Y, pararosaniline, crystal violet $(\mathrm{CV})$ and Ponceau 2R references were purchased from Sigma Aldrich. Rosaniline Hydrochloride was obtained from Eimer and Amend. Methyl violet (MV) was purchased from Fluka Chemical Corp. Cotton scarlet and brilliant scarlet were obtained from Standard Colors. Samples of $\mathrm{CV}$ applied on paper were prepared in the past at the Metropolitan Museum of Art laboratories exposing them to different light doses by means of transmission step wedges.

\section{Surface enhanced Raman spectroscopy}

The prints were primarily investigated by surfaceenhanced Raman spectroscopy (SERS). The silver colloid was prepared by microwave supported reduction of $\mathrm{Ag}_{2} \mathrm{SO}_{4}$ in the presence of glucose and sodium citrate [4]. The colloid was concentrated 5 times by centrifuging $1 \mathrm{ml}$ of colloid and replacing $950 \mu \mathrm{l}$ of the supernatant liquid with $150 \mu \mathrm{l}$ of ultrapure water.

Samples were obtained from the prints by removing fragments of single paper fibres $(\sim 100 \mu \mathrm{m}$ in length) using a tungsten needle and/or tweezers. To minimize the damage to the prints, fibres already raised from the surface or partially detached were selected. SERS analysis 
was carried out following a multistep protocol described in details elsewhere. ${ }^{1}$ This approach was fundamental for the detection of dyestuff mixtures (such as carminic acid and eosin). Briefly, the sample was treated with $\mathrm{HNO}_{3}$ $(\sim 1 \mu \mathrm{l}$ of $1 \%$ solution in water) and then $2 \mu \mathrm{l}$ drop of colloid was added. After the SERS spectra were collected, the colloid and acidic solution were removed from the sample. In the second step, the same sample was exposed to HF vapour. After the treatment, a $2 \mu \mathrm{l}$ drop of colloid was delivered onto the sample, followed by $\sim 0.4 \mu \mathrm{l}$ of $0.1 \mathrm{M} \mathrm{KNO}_{3}$ solution to induce aggregation.

SERS spectra were acquired using a Bruker Senterra Raman instrument, exciting the sample at $488 \mathrm{~nm}$ (Spectra Physics Cyan) through a $20 \times$ long working distance objective, keeping the laser power on the specimen below $0.2 \mathrm{~mW}$. The laser beam was focused inside the silver nanoparticle drop. All the spectra were acquired for $30 \mathrm{~s}$, with a resolution of $3-5 \mathrm{~cm}^{-1}$.

\section{Complementary techniques}

Various other non-destructive spectroscopy techniques were employed in the course of this study to obtain the full characterization of the various coloured areas.

The same Raman instrument described previously was used to perform micro-Raman spectroscopy. The $785 \mathrm{~nm}$ diode laser was focused through a $50 \times$ long working distance objective, with a laser power on the sample kept below $5 \mathrm{~mW}$. This method gave good results with inorganic pigments but it also allowed us to identify synthetic naphthol colorants.

Micro X-ray fluorescence (micro-XRF) measurements were performed using a Bruker ARTAX 400 instrument by means of an unfiltered $\mathrm{Rh}$ radiation at $50 \mathrm{kV}$, $700 \mu \mathrm{A}$, with a $1 \mathrm{~mm}$ collimator, and with $120 \mathrm{~s}$ live-time acquisition.

Fiber optics reflectance spectroscopy (FORS) was performed with an Ocean Optics USB 2000+ UV-VISES spectrometer, employing a halogen light source (T1300-UV-VIS), both coupled with $300 \mu \mathrm{m}$ core UV/ SR fibers. The distance between the head of the fiber and the sample was kept constant at $1 \mathrm{~mm}$. The reflected light was acquired in the $350-850 \mathrm{~nm}$ range for $10 \mathrm{~ms}$.

\section{Results and discussion}

An extensive survey of the pigments used for Japanese prints spanning the period 1848-1898 was carried out with a multi-analytical approach. Micro-XRF [5], micro-Raman [6] and FORS [7] were performed

\footnotetext{
${ }^{1}$ Forthcoming article: Cesaratto A. et al. 'Sample treatment considerations in the analysis of organic colorants by surface-enhanced Raman scattering. Part II: synthetic dyes'.
}

non-destructively directly on the prints, while SERS [8] was performed on fragments of paper fibres detached from the surface, as described in the previous section. The complete list of the pigment materials identified is reported in the Additional file 1: Table S2; additionally, a previous published article has been focused on the study of the green and yellow areas [9]. In the present work we are going to focus our attention on the identification of organic colorants. The new findings confirm, complete and deepen Atsuka Yamato's seminal unpublished study on the same subject [10].

\section{A timeline for red and purple dyestuffs}

Accurate and complete identification of the dyestuffs in datable prints is fundamental to building a timeline for determining both the continued use of existing colorants and the introduction of new ones to the Japanese market in the years of transition from the Edo to the Meiji periods (1860s through 1890s).

The purple and red dyes that were identified in the prints studied are listed in Table 1. In the course of the following discussion, SERS and Raman spectra of representative dyes will be shown, normalized to the maximum peak. When peak positions are listed, the relative intensities of the peaks used to compare the material with the references will be expressed as follows: vs = very strong; $\mathrm{s}=$ strong; $\mathrm{m}=$ medium; $\mathrm{w}=$ weak; $\mathrm{vw}=$ very weak; $\mathrm{sh}=$ shoulder. In some cases, the identification was further supported by micro-XRF and FORS analysis.

\section{Purple: the first synthetic dyestuffs in Japanese prints}

The leading protagonist of the color revolution of the Meiji period was purple. First came rosaniline, which was found consistently in the purple areas of prints dated from 1864 to 1878 (18 out of 18 prints). Evolving from experiments by Natanson (1856) and August Wilhelm von Hofmann (1858), it was first patented and manufactured in 1859 in France using the process of Verguin, under the name of fuchsine, later popularly known as magenta [12] Rosaniline was followed by pararosaniline in 1869 [11, 13], which like rosaniline is a homolog of basic fuchsine. The two compounds differ for the number of methyl group: pararosaniline is the non-methylated homolog, while rosaniline is characterized by one methyl group. Since the SERS spectra of the two compounds are identical [14], we were not able to distinguish the two, and have simply identified all findings of these dyes as 'magenta', leaving open the possibility that the compound used after 1869 may have been pararosaniline.

The SERS spectrum of magenta obtained from a print produced in 1873 is shown in Fig. 2a. Signals of reference magenta were detected at $247 \mathrm{w}, 347 \mathrm{w}, 427 \mathrm{w}, 825 \mathrm{w}$, 
Table 1 List of natural and synthetic dyestuffs identified in the Japanese woodblock prints considered in this study

\begin{tabular}{|c|c|c|c|c|c|}
\hline Dye & Molecule & Color Index \# & Chemical class & Origin & Introduction $^{d}$ \\
\hline Rosaniline & - & Basic red 14 & Triarylmethane & Synthetic & $1856-1858$ \\
\hline Pararosaniline & - & Basic red 9 & Triarylmethane & Synthetic & 1869 \\
\hline Methyl violet & - & Basic violet 1 & Triarylmethane & Synthetic & $\begin{array}{l}\text { Synthetized: } 1861 \\
\text { As artists' material: } 1866\end{array}$ \\
\hline Crystal violet & - & Basic violet 3 & Triarylmethane & Synthetic & 1883 \\
\hline Safflower red & Carthamine & Natural red 26 & Chalcone & Natural (vegetal) & Antiquity \\
\hline Carmine & Carminic acid & Natural red 4 & Anthraquinone & Natural (animal) & $\begin{array}{l}\text { Americas: antiquity } \\
\text { Europe: } 1518\end{array}$ \\
\hline Eosin $Y$ & - & Sodium salt: acid red 87; free acid: solvent red 43 & Xanthene & Synthetic & 1871 \\
\hline Ponceau 2R & - & Acid red 26 & Naphthol & Synthetic & 1878 \\
\hline Brilliant scarlet $^{\mathrm{b}}$ & - & Acid red 18 & Naphthol & Synthetic & 1878 \\
\hline Cotton scarlet $^{c}$ & - & Acid red 73 & Naphthol & Synthetic & 1882 \\
\hline
\end{tabular}

a Listed in the Colour Index also as scarlet 2R, rainbow scarlet, new Ponceau 4R, acid scarlet, naphtharene scarlet 2R, amacid scarlet 2R lake scarlet 2R [11]

b Listed in the Color Index also as scarlet, rainbow scarlet, new coccine, brilliant ponceau, wool scarlet, pontacyl scarlet, crocein scarlet [11]

c Listed in the Color Index also as brilliant croceine, croceine scarlet, paper scarlet, blackley scarlet, carmoisine, croceine, paper red, cocceine, ponceau [11]

d The term introduction refers to the introduction in the Western world, unless otherwise specified

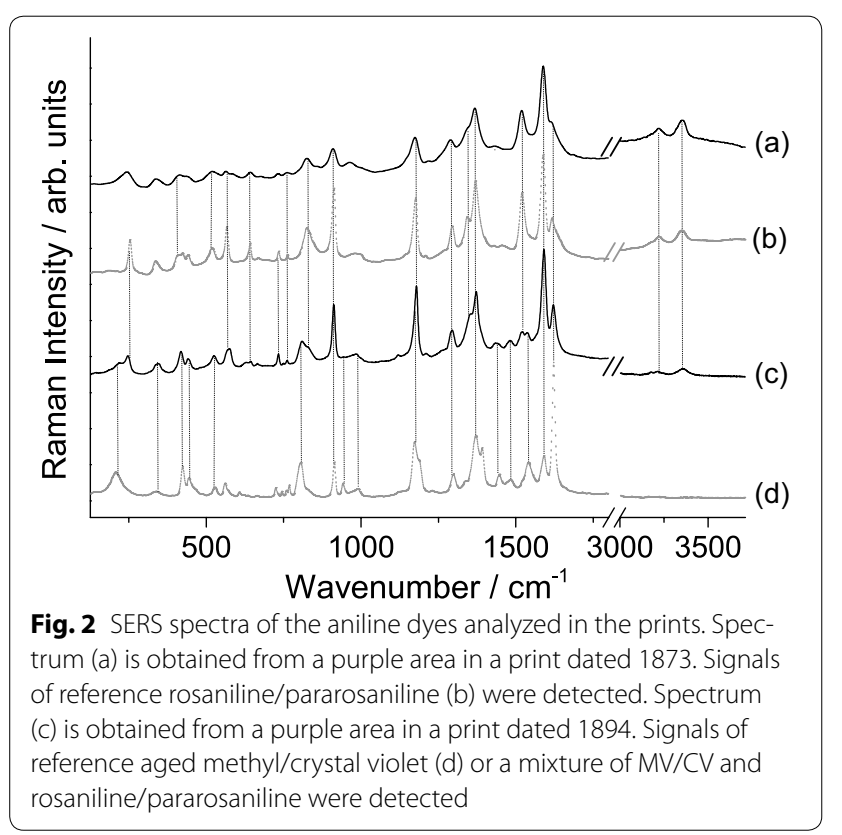

915 w, 1177 m, 1287 m, 1348 sh, 1370 s, 1520 m, 1587 vs, $1617 \mathrm{sh}, 3222 \mathrm{w}, 3347 \mathrm{w} \mathrm{cm}^{-1}$.

By 1875 a change in the purples areas became evident. Two purple aniline dyes belonging to the triarylmethane family were introduced into the market at the end of the nineteenth century: methyl violet (basic violet 1 ) in 1866 (invented in 1861) and crystal violet (basic violet 3) in 1883. The SERS spectra of the two compounds are identical, therefore it is not possible to distinguish between them with a SERS-based approach [14, 15]. Furthermore, they are badly prone to photo-fading processes, in particular, N-demethylation progressively leads to the formation of the completely de-methylated compound (pararosaniline) [16, 17]. As a result, the SERS spectrum of the aged compounds is slightly modified, and it progressively assumes some features typical of pararosaniline [14]. For purples in prints dated between 1875 and 1883 , it is not possible to differentiate aged methyl violet or a mixture of methyl violet and magenta. Prints dated between 1883 and 1895 and containing triarylmethane purples could have been realized with methyl or crystal violet, which has aged overtime, or with a mixture of them with magenta. The mixtures could have been obtained on purpose or not, since the synthesis methods of the time could have led to the production of materials characterized by various degree of methylation. In particular, as regards the spectrum shown in Fig. 2c, signals of methyl/crystal violet (Fig. 2d) were detected at $219 \mathrm{~m}$, $341 \mathrm{~m}, 417 \mathrm{~m}, 444 \mathrm{~m}, 525 \mathrm{w}, 804 \mathrm{~s}, 914 \mathrm{~s}, 941 \mathrm{~m}, 989 \mathrm{w}$, $1298 \mathrm{~m}, 1368$ vs, $1481 \mathrm{w}, 1539 \mathrm{~m}, 1589$ vs, $1622 \mathrm{~s} \mathrm{~cm}^{-1}$. Signals of magenta (Fig. 2b) were detected at $246 \mathrm{~m}$, $417 \mathrm{~m}, 444 \mathrm{~m}, 572 \mathrm{~m}, 640 \mathrm{vw}, 733 \mathrm{w}, 761 \mathrm{vw}, 824 \mathrm{sh}, 911$ vs, 1177 vs, 1293 s, 1353 sh, 1371 vs, 1436 w, 1519 w, 1589 vs, $1622 \mathrm{~s}, 3202 \mathrm{vw}, 3351 \mathrm{w} \mathrm{cm}^{-1}$.

\section{Cochineal carmine replaces safflower, 1869}

The extensive use of red is invariably cited as defining characteristic of Meiji prints. The dominant red in the nishiki-e multicolour print medium from its introduction in 1765 was safflower (natural red 26, benibana in Japanese), an ancient dye in Japan that was used on much wider scale in the Edo period as textile dye and for cosmetics $[18,19]$. 


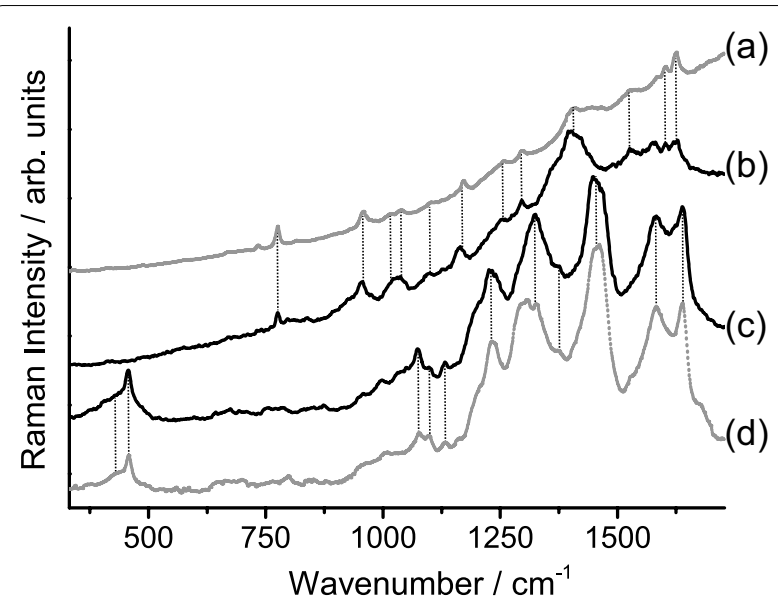

Fig. 3 SERS spectra of the natural dyestuffs analyzed in the prints. Spectrum (b) is obtained from a red area in a print dated 1865. Signals of reference safflower red (a) were detected. Spectrum (c) is obtained from a red area in a print dated 1872. Signals of reference carmine (Winsor \& Newton carmine lake, spectrum d) were detected

Carthamine, the main coloring matter of safflower red, was detected in this work on 9 out of 11 prints dated earlier than 1869. The SERS spectrum obtained from a print produced in 1858 is shown in Fig. 3b. Signals of safflower (Fig. 3a) red were detected at 775 s, $955 \mathrm{~m}, 1016 \mathrm{sh}$, 1037 w, 1096 vw, 1165 s, 1255 vw, 1295 m, 1403 s, 1526 w, $1601 \mathrm{w}, 1624 \mathrm{~m} \mathrm{~cm}^{-1}$.

We discovered that in the year 1869, however, safflower was completely replaced by imported cochineal carmine. This change had been hypothesized by Yamato [10], but we were able to make a positive confirmation of carmine as the dominant red in Japanese prints from early 1869, used continuously thereafter until 1891. In addition, carmine has been detected in two prints of 1864, proving that the colorant was available in Japan at that time, although it was not found in any other print before 1869 .

The SERS spectrum of carmine obtained from a print produced in 1872 is shown in Fig. 3c. Signals of carmine (Fig. 3d) were detected at $431 \mathrm{sh}, 456 \mathrm{~m}, 1073 \mathrm{~m}$, $1097 \mathrm{vw}, 1132 \mathrm{w}, 1129,1460 \mathrm{vs}, 1580 \mathrm{~s}, 1638 \mathrm{~s} \mathrm{~cm}^{-1}$.

Two red insect dyes were known in the late Edo period, the more common and widely used of which was lac, produced in India and Southeast Asia, and known and used in China since ancient times. It was imported to Japan in considerable quantity in the late Edo period for textile dyeing and has also been confirmed in a number of ukiyo-e paintings [20], but it has yet to be found in woodblock prints. Meanwhile carmine (cochineal or carmine cochineal, natural red 4) is a red dye extracted from the female of the cochineal scale insect (Dactylopius coccus L. Costa) native to Central and South America. It was introduced in Europe in 1518 and it became common by
1549 [21]. It was shipped by the Spanish from Acapulco to Manila, and on to China by early seventeenth century, and could have easily found its way to Japan [22]. The best-documented use of cochineal in Japan, however, was not as a dye but in the form of cochineal-dyed woolen cloth, which was much prized by samurai for making into garments [23, 24]. The rarity of the use of cochineal was probably due to its higher cost than the more easily available lac.

The sudden replacement of safflower by cochineal carmine in 1869 can probably be explained as the intersection of two trends, on the one hand the decline of safflower production in Japan, and at the same time the availability of carmine on the world market at increasingly lower prices.

A study of safflower cultivation in its most important region of production in Japan, the Mogami River valley of the northeast Tohoku district (now Yamagata Pref.) reveals that following the opening of Japanese ports to world trade in 1859, native safflower was increasingly threatened by imports of the Chinese product, which was less expensive and apparently often of higher quality. At the same time, the pressure from the Tokugawa government to generate exports by the production of silk and tea led to the replacement of safflower fields in Tohoku with mulberry orchards to provide leaves for feeding silkworms [25].

At the same time, world production of cochineal was rapidly growing in the 1860 s, both in Guatemala, which had been the major Central American source for export to Europe since the 1840s [26], but also in the Canary Islands, where cultivation of the cochineal insect and the opuntia cactus on which it feeds had become a boom by the late 1860s (and soon after a bust) [27]. The exact trade route of cochineal to Japan is not yet known, but in all likelihood it was processed in Europe, most likely in England or France, into the laked form of cochineal carmine ready to use as a pigment, and then shipped to Yokohama. The primary reasons for the immediate success of carmine were probably both lower cost and greatly enhanced ease of printing, but also perhaps the appeal of the quality of the rich red colour that it yielded.

The presence of carmine has been further confirmed by the band at about $550 \mathrm{~nm}$ in FORS spectra, typical of insect dyestuffs [28].

\section{The introduction of eosin, 1877}

Starting from 1877, we see the introduction of eosin. Eosin (acid red 87/solvent red 43), characterized by a brilliant pink color, was first synthetized by Caro in 1871 by brominating fluorescein and converting it in the disodium salt; therefore, it is a fluorone dye of the xanthene group [29]. It was widely used in the West as an artists' 


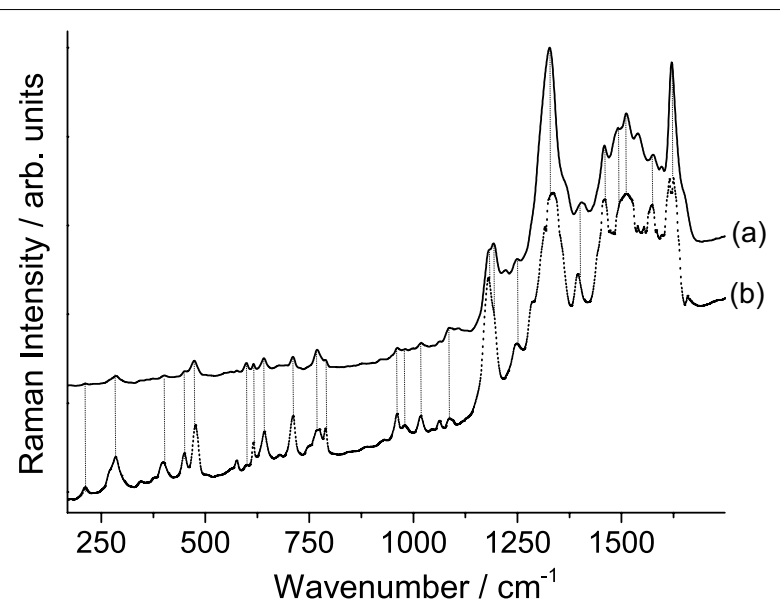

Fig. 4 SERS spectrum of eosin analyzed in the prints. Spectrum (a) is obtained from a red-pink area in a print dated 1881. Signals of reference eosin (b) were detected

material, often in the form of the lake pigment known as Geranium lake [30] and it was one of the most common lithographic inks [31, 32]. The SERS spectrum of eosin obtained from a print produced in 1881 is shown in Fig. 4a. Signals of eosin (Fig. 4b) were detected at $211 \mathrm{vw}$, $284 \mathrm{w}, 398 \mathrm{vw}, 450 \mathrm{w}, 472 \mathrm{~m}, 597 \mathrm{w}, 616 \mathrm{w}, 642 \mathrm{~m}, 710 \mathrm{~m}$, $768 \mathrm{~m}, 789 \mathrm{sh}, 960 \mathrm{w}, 1016 \mathrm{vw}, 1063 \mathrm{vw}, 1087 \mathrm{w}, 1182 \mathrm{~s}$, 1193 s, 1251 m, 1328 vs, 1405 m, 1481 m, 1512 s, 1538 m, $1575 \mathrm{~m}, 1620 \mathrm{vs} \mathrm{cm}^{-1}$. Eosin was also indicated by the identification of $\mathrm{Br}$ through micro-XRF analysis in the same areas where the samples for SERS were obtained.

Even after its introduction to Japanese woodblock print no later than 1877, 6 years after it was synthetized for the first time in Europe, eosin did not replace carmine, but was often used in mixture with it for dark reds, while it was used alone for pinks. For a more detailed overview of the analysis of eosin and carmine mixtures refer to the forthcoming article by Cesaratto et al. (see footnote 1).

\section{The appearance of naphthol acid red dyes, 1889}

In the second half of 1889 a new class of red synthetic colorants makes its appearance on the Japanese market: naphthol reds, which suddenly replaced carmine. The naphthol colorant Ponceau 2R (acid red 26) was found on a print dated mid-1889. Ponceau $2 \mathrm{R}$ is a mono-azo $\beta$-naphthol colorant, discovered by $\mathrm{H}$. Baum in 1878. It can be identified by its characteristic Raman peaks at $474 \mathrm{~m}, 491 \mathrm{sh}, 745 \mathrm{vw}, 939 \mathrm{~m}, 1133 \mathrm{vw}, 1245 \mathrm{vs}, 1341 \mathrm{~s}$, $1380 \mathrm{w}, 1493 \mathrm{~m}, 1582 \mathrm{w}$ and $1610 \mathrm{~m} \mathrm{~cm}^{-1}$ [33].

Ponceau red 2R was soon followed by cotton scarlet (acid red 73), detected by micro-Raman spectroscopy in the red areas of a print dated to 1892 and then used with consistency in the following years. Cotton scarlet, a $\beta$-naphthol colorant belonging to the dis-azo group, was first synthetized in 1882 by Limpach and in 1883 by $\mathrm{H}$. Hoffmann. The Raman spectrum of cotton scarlet obtained from a print produced in 1894 is shown in Fig. 5A-a. Signals of cotton scarlet Fig. 5A-c were detected at $1140 \mathrm{~s}, 1186 \mathrm{vw}, 1238 \mathrm{~s}, 1420 \mathrm{~s}, 1443 \mathrm{~s}$, $1464 \mathrm{~m}, 1500 \mathrm{~m}$ and $1596 \mathrm{vs} \mathrm{cm}^{-1}$ [33].

Another naphthol red, brilliant scarlet (acid red 18), was detected for the first time in a print dated 1895. Like ponceau $2 \mathrm{R}$, brilliant scarlet is a $\beta$-naphthol colorants belonging to the mono-azo group, synthetized for the first time by Baum in 1878. The Raman spectrum of brilliant scarlet obtained from a print produced in 1897 is shown in Fig. 5B-a. Signals of brilliant scarlet (Fig. 5B-c) were detected at $500 \mathrm{w}, 694 \mathrm{w}, 942 \mathrm{~m}, 1238 \mathrm{vs}, 1342 \mathrm{w}$, 1361 vs, 1399 vw, 1421 vw, 1439 m, 1457 m, 1512 s, 1571 vs, $1590 \mathrm{~m} \mathrm{~cm}^{-1}$ [33].

Naphthol reds give a bright red hue. Because of their high solubility in water they bleed through the paper (and the backing, if any), and are characteristically visible on the back of the prints, as can be clearly seen in Fig. $5 \mathrm{C}$. They were adopted in Japan about 10 years after they had become available on the Western market.

It is worth noting that among the various commercial names used for these three naphthol compounds, many contain the term 'scarlet', as reported in the Colour Index [11]. Sukaretto, the Japanese transliteration of 'scarlet', has been attested in an article published in 1890 on the newspaper Yomiuri shinbun, in which the author laments the drop in the quality of woodblock printing caused by the introduction of the new synthetic colorants [34]. In 1894 the same word is recorded by Koizumi Eijirō, who describes it as "a red dye made of naphthol (nafusōru), with truly many varieties, of which here are a few with their names and chemical formulas" [35]. Naphthol reds were also very common inks in the early phases of chromolithography (ca. 1890-1920) [36-38]. In lithographic inks the colorant is usually mixed with a 'varnish' and several additives to improve the overall quality of the material. The strong fluorescent background which characterizes the Raman spectra of the naphthol reds collected from the prints, as can be seen in Fig. 5A-a and $\mathrm{B}-\mathrm{a}$, could be ascribed to the intrinsic complexity of the ink mixture [32, 36, 37]. Furthermore, the consistent detection of $\mathrm{Ba}$ in the XRF analysis in the area where naphthol red was detected by micro-Raman points to the use of barium white $\left(\mathrm{BaSO}_{4}\right)$, a common ingredient of lithographic inks as an extender or as a substrate of the lake pigment, as attested in the past [37]. Barium is most likely to be present as $\mathrm{BaSO}_{4}$, used as extender, since the high sensitivity to water of the red areas points toward the use of the material as a free colorant instead of the lake pigment. The presence of the Raman peak of barite, 

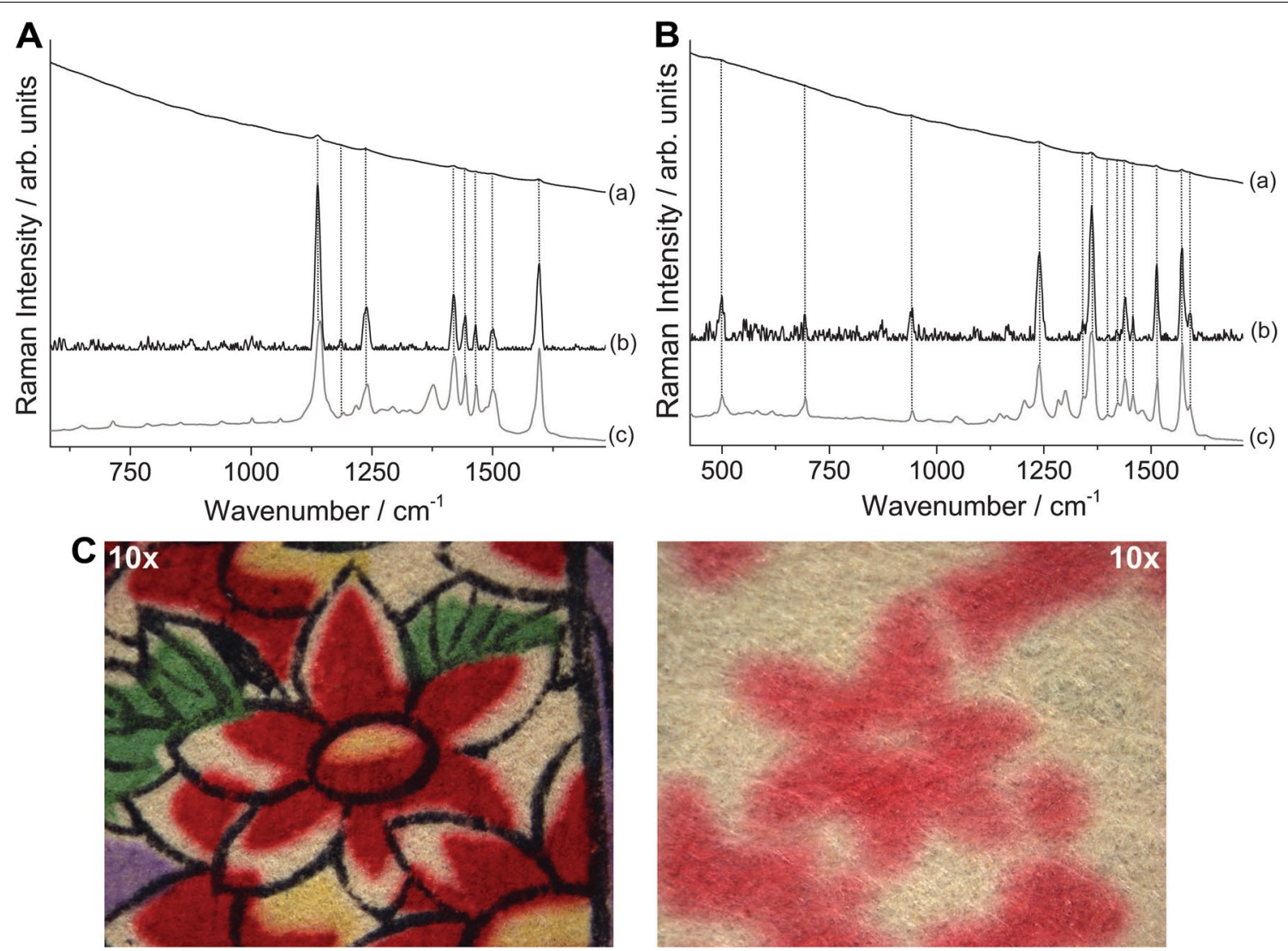

Fig. 5 Raman spectra of the naphthol reds analyzed in the prints. A Raman spectrum (a) obtained from a red area in a print dated 1894. Signals of reference cotton scarlet (c) were detected. B Raman spectrum (a) obtained from a red area in a print dated 1897. Signals of reference brilliant scarlet (c) were detected. Due to the high fluorescent background, the spectra (a) have been background subtracted (b). C Close-ups (10x magnification) of a red area printed with cotton scarlet: the colorant has bled through the paper and it is visible on the verso (right)

at around $987 \mathrm{~cm}^{-1}$, in some prints seems to confirm this hypothesis. Since barium white is an inexpensive pigment and produces inferior extenders, it was sometime used in cheaper grades of ink. It was also used in gloss white, a $25 \%$ alumina hydrate- $75 \% \mathrm{BaSO}_{4}$ mixture, which produces a semi-opaque extender [36].

The results of our survey were used to build the timeline presented in Fig. 6.

It bears special emphasis that all the novel colorants introduced into Japanese prints in the later nineteenth century were commonly used as inks in chromolithography $[32,36]$. Chromolithography blossomed in the West in the later nineteenth century, abetted by the increased variety of color shades enabled by the early synthetic colorants [39]. While in the early history of chromolithography printers were accustomed to preparing their own inks, from 1860 on, factories specialized in the production of lithographic inks were established; by 1890 they were providing printers with ready-to-use inks both in Europe and USA [39].

\section{Mixtures of pigments and dyes}

Throughout the group of prints studied, colorants are often found in combination, either by physically mixing two or more substances before application to the woodblock, or by over-printing different colorants from the same block.

The complete list of mixtures of pigment materials is reported in Table 2.

For the color purple, which was the first to be transformed by a synthetic dye with the introduction of rosaniline (magenta) in 1864, the traditional palette had always used a mixture of red and blue, which from the 1830s has been shown by the work of Yamato [10] to have been predominantly a combination of safflower red with either dayflower blue (extracted from the flowers of Commelina communis) or occasionally indigo, and in rare cases, Prussian blue. Our results confirmed one case, dated 1859, of the mixing of safflower and Prussian blue.

Our results have demonstrated that the introduction of magenta as a new purple in 1864 always involved a mixture with Prussian blue, presumably to adjust the 


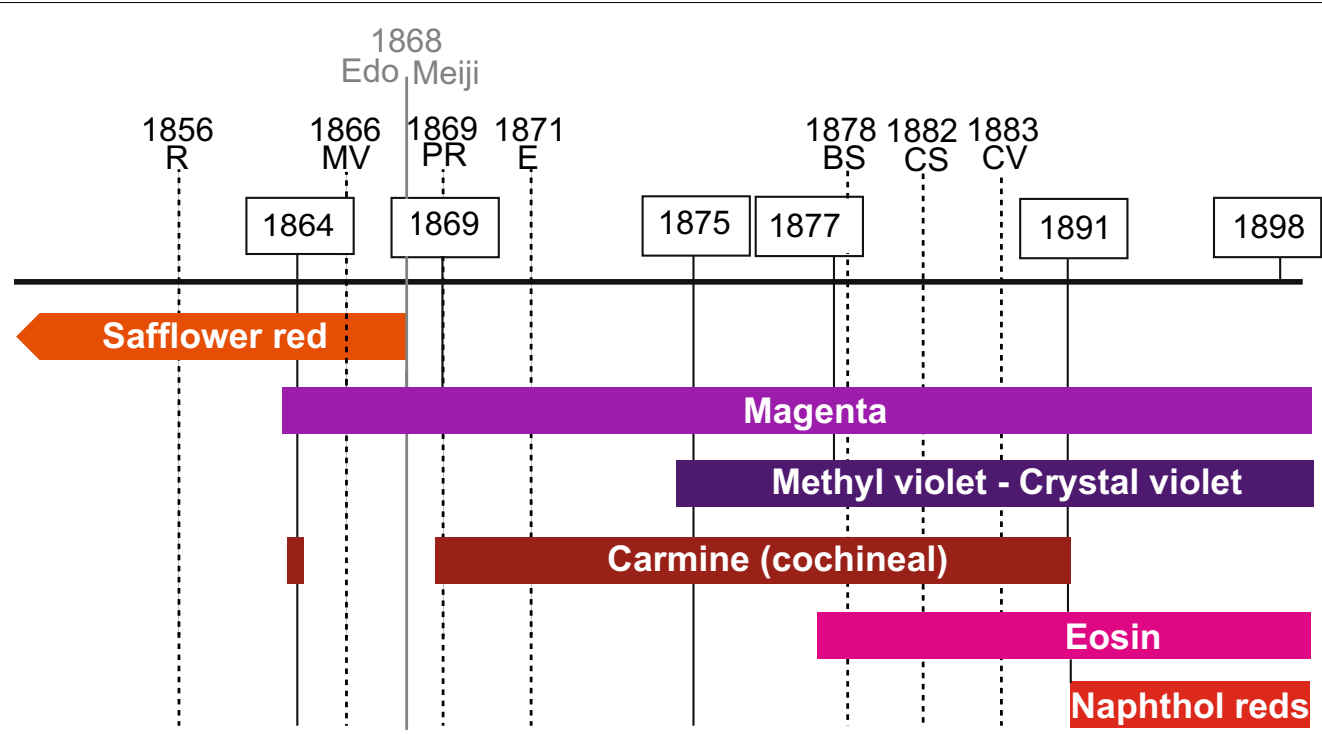

Fig. 6 Timeline for the use of natural and synthetic dyes in Japan during the late Edo and early Meiji periods, reconstructed on the basis of the analysis reported in this study. (R rosaniline, MV methyl violet, $P R$ pararosaniline, E eosin, BS brilliant scarlet, CS cotton scarlet, CV crystal violet)

Table 2 Pigment materials used in combination in the Japanese prints considered in this study

\begin{tabular}{|c|c|c|c|}
\hline \multirow[t]{2}{*}{ Colors } & \multicolumn{2}{|l|}{ Organic dyestuffs } & \multirow{2}{*}{$\begin{array}{l}\text { Inorganic pigments } \\
\text { - }\end{array}$} \\
\hline & Natural & Synthetic & \\
\hline \multirow[t]{8}{*}{ Red } & Safflower red & - & Vermilion-iron oxide \\
\hline & Carmine & - & Vermilion-iron oxide \\
\hline & Carmine & Eosin & - \\
\hline & Carmine & Eosin & Vermilion \\
\hline & - & Eosin & - \\
\hline & - & Naphthol red & Vermilion \\
\hline & - & Naphthol red_eosin & - \\
\hline & - & Naphthol red_eosin & Vermilion \\
\hline \multirow[t]{3}{*}{ Purple } & Safflower red & - & Prussian blue \\
\hline & Magenta $^{\mathrm{a}}$ & - & Prussian blue \\
\hline & Magenta—methyl/crystal violet ${ }^{\mathrm{b}, \mathrm{c}}$ & - & - \\
\hline
\end{tabular}

a Rosaniline before 1869, rosaniline/pararosaniline after 1869

b Methyl violet before 1883, methyl/crystal violet after 1883

c Refer to the previous paragraph for a complete discussion about this possible mixture

hue and saturation of the printed color. This mixing is clearly visible comparing the front and the back in a print dated 1870, reported in Fig. 7. Magenta has been more absorbed by the paper substrate, making the back appear more pink, while the front is a deep purple tone. Prussian blue was detected by the two characteristic Raman peaks at 2102 and $2154 \mathrm{~cm}^{-1}$.

The different issues of the possible mixtures of rosaniline and pararosaniline, or of methyl violet and crystal violet, have been discussed in detail in a previous paragraph.
For the color red, the work of Yamato [10] has shown that from the early 1820 s the basic safflower red was almost always enhanced by admixture with either vermilion (J. shu), iron oxide (in the synthetic Japanese form known as bengara), or red lead (J. entan), or by various combinations of these three. Most common was vermilion (HgS), which became even more common in the 1860s, a phenomenon that Yamato attributes to the opening of Yokohama to international trade from 1859, and the resultant collapse of government control over the market for vermilion imported from China. 

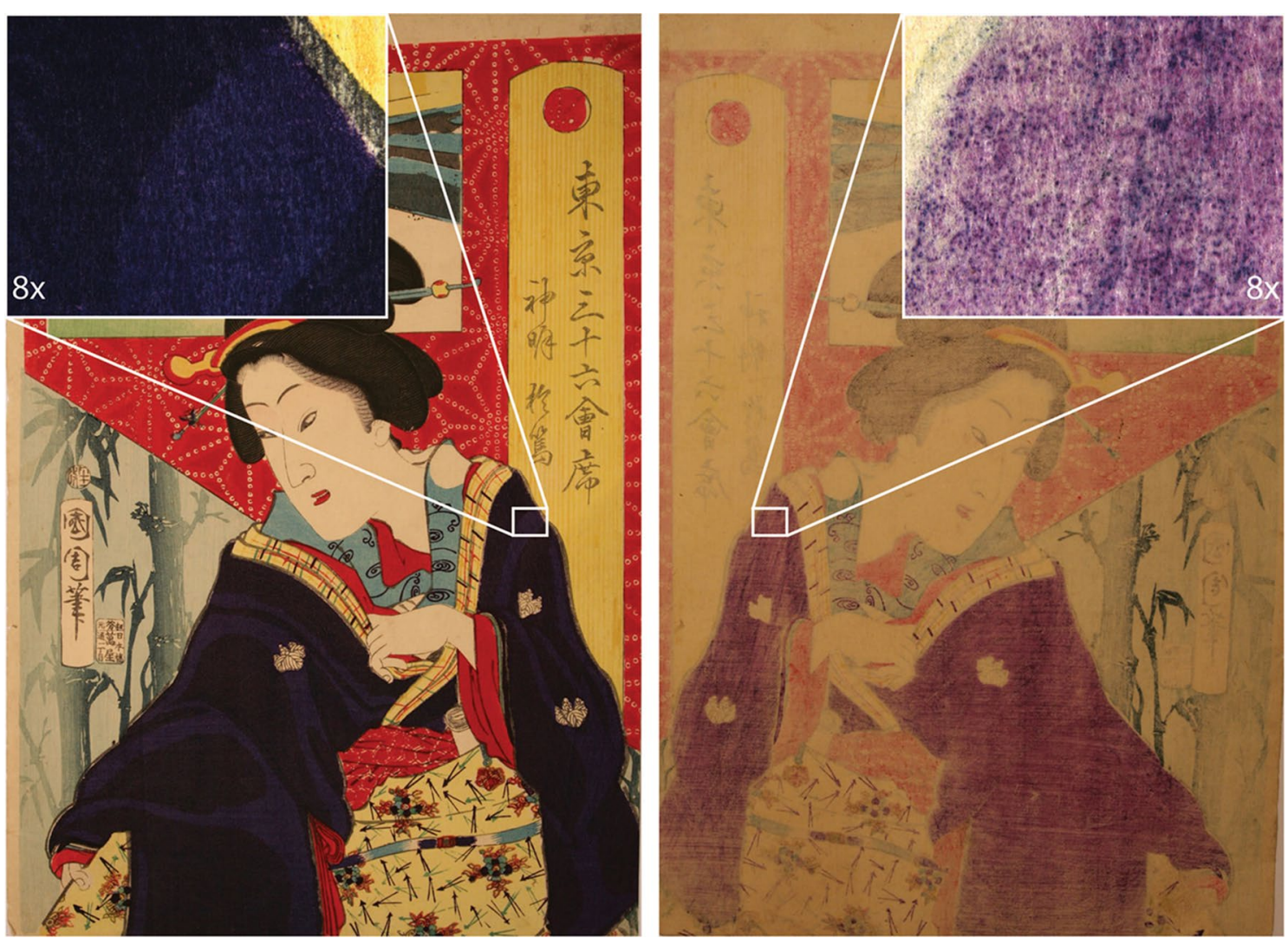

Fig. 7 Images of the front and the back of a print dated 1870. Close-ups microscope images of the purple areas (8x magnification)

This study confirmed the frequent mixing of vermilion with safflower red. Vermilion was identified by its strong and characteristic Raman spectrum (the high Raman cross section of vermilion generally makes its detection possible over the fluorescence background) and the presence of $\mathrm{Hg}$ detected through XRF. Safflower might have also been used in combination with iron oxide (bengara), as suggested by the detection of Fe through XRF. Bengara has also been shown to have been widely used in Japanese ukiyo-e paintings [20].

In the next critical transition, when imported cochineal carmine replaced safflower red in 1869, this new colorant was also routinely mixed with vermilion. In such cases, the Raman signal presents a strong fluorescent background, but the vermilion peaks are clearly detectable.

In a few cases, a carmine-bengara mixture can also be deduced, from a finding of Fe by XRF. It seems that bengara may have been used with both safflower and carmine to produce a darker red hue. The use of bengara could not be confirmed in this study by Raman analysis, since the strong fluorescence caused by the organic colorants generally overwhelms completely the weak Raman signal typical of an iron oxide pigment, especially when excited at $785 \mathrm{~nm}$.
A different type of mixture was revealed by the finding of carmine in combination with eosin from 1877, the first case of mixing a natural organic substance with a new imported synthetic dye. It was possible to detect these two organic colorants in mixture through a multi-step SERS procedure described in detail elsewhere (see footnote 1). Furthermore, these two colorants were also used together with vermilion. The reasons for combining eosin with carmine are unclear; perhaps it was a matter of cutting costs, or possibly a way of adjusting the hue of the resulting red in a bluish direction.

Similarly, the naphthol reds that appeared from 1889 were used in mixture with vermilion in several cases. This seems to have been a common practice in the production of lithographic inks, where it was most likely added to increase the opacity of the ink [37]. Mixtures of naphthol red and eosin, sometimes with vermilion added, were also detected in our study, through the combination of XRF, micro-Raman and SERS analysis.

\section{Conclusions}

Our goal was to establish a timeline for the introduction of synthetic organic dyes into Japanese nishiki-e color woodblock prints from the final decade of the Edo 
period (1600-1868) through the first three decades of the Meiji reign (1868-1912), when the medium was at its historical peak. By combining SERS microanalysis with non-destructive micro-XRF, micro-Raman and FORS, we were able to build a timeline accurate to the year and often to the time of year for the introduction of these new dyes that were at the forefront of the global "color revolution".

Our basic finding is that, contrary to the widespread notion that aniline dyes suddenly replaced "traditional" colorants soon after the opening of Japan to international trade in 1859, the process was gradual and dye-specific, and that the overall impact of these new colorants has been exaggerated, with most of the existing dyes continuing in use.

The arrival in Japan of the revolutionary new aniline textile dyes that were triggered by William Henry Perkin's discovery and subsequent manufacture of purple "mauveine" in 1856 are documented earliest for in the region of Takasaki, a silk-producing region north of Edo-Tokyo, probably no earlier than 1863 [40], notwithstanding an undocumented report of dyeing with aniline purple in Kyoto in 1862 [41]. Our finding of rosaniline (magenta) in a print of the second month of 1864 is congruent with this date and suggests that this dye was probably obtained by woodblock printers from foreign merchants in Yokohama.

We also found that the reddish magenta was always used in mixture with Prussian blue, thus continuing a long-standing practice by which purple was achieved by mixing the dominant safflower red with various blue dyes, also including dayflower and indigo.

Meanwhile, by far the most striking import of a foreign colorant was not a modern chemical product, but rather the well-established and prestigious red insect dye from the cochineal insect of Mesoamerica, introduced to Europe in the early sixteenth century and widely used for dyeing both silk and wool, and in the form of carmine lake for oil paintings. In early 1869 , the second year of Meiji, cochineal carmine suddenly replaced safflower as the dominant red in nishiki-e prints, continuing for two decades until 1889.

The next synthetic dye after magenta in 1864 was methyl violet in 1875 , creating without mixture an assertive purple that became widely used (possibly substituted by the similar crystal violet from 1883), and the first aniline dye to add a distinctly new color to nishiki-e. Next came eosin in early 1877 , used alone for its distinctive bright pink hue (perfect for cherry blossoms) and as an additive to cochineal carmine, perhaps to render it more bluish.

Overall, however, the most dramatic impact of these first changes was less in the color qualities of the new imported colorants but rather in the quantity with which they could be used, because of high tinting strength relative to cost, and an ease of printing that probably reduced labor costs. This was true above all of the advantage that carmine had over safflower, resulting in an immediate and sharp increase in the sheer area over which cochineal red was applied from 1869 on, most conspicuously in solid red backgrounds (cf. Figs. 1 and 7), or in wide bands of red gradation down from the upper edge or up from the horizon. Such uses were known in the era of safflower red, but were reserved for luxury editions given the cost of the dye and the effort required by numerous overprintings to achieve a deep color.

It would not be until 1889, two decades into the Meiji period, that synthetic organic dyes truly worthy of such common epithets as "harsh" and "garish" appeared in the form of naphthol "acid red" dyes from 1889. As it happened, however, it was just at this time that a new tendency was emerging in nishiki-e, in the direction of a more painterly feel, eliminating solid backgrounds and bands of gradation for a lighter, more modern touch. The new acid reds were used but in more restrained ways, as accents rather than broad swaths.

In broader historical perspective, the changes in nishiki-e colorants in the Meiji period appear considerably less dramatic than usually assumed. A broad shift to more light-fast and saturated colorants was already underway from the 1820 s, given a sudden boost with the introduction high-quality low-cost Chinese-produced Prussian blue in quantity after 1829 that really did constitute a color "revolution" in the landscapes of Hokusai and Hiroshige [42]. The sudden availability of similarly highquality low-cost cochineal carmine on the global market from 1869 was also dramatic, but less of a revolution in the quality of the red than in the abandon with which it could be printed. Our results have shown that perhaps the single greatest color change in Meiji was rather for purple, always a challenge before synthetic dyes became available.

A further key continuity from Edo to Meiji was the persistence of all the same "traditional" colorants used in nishiki-e since the 1830s with the exception of safflower and dayflower blue, both fickle colors prone to fading that could not survive under the brighter light of Meiji.

Our results suggest a range of new approaches to the study of Meiji prints. Many questions remain about the costs of colorants and their availability on world and local markets, and about the ways in which printers varied their techniques to make the most of available materials. The results also suggest that rather than condemning "Meiji red" as an aesthetic disaster, more attention should be paid to indigenous meanings of red as the color of festivity, sacrality, and healing powers, as well 
as a manifestation of the power of the new Meiji state to mobilize those traditional sentiments.

\section{Additional file}

Additional file 1: Table S1. Table indicating: date of production, artist and title of the Meiji prints collection analyzed in this study. The prints in italic are part of the Metropolitan Museum of Art collection. Table S2. Table indicating: XRF, Raman and SERS analysis of the pigment materials used in the Meiji prints collection considered in this study.

\section{Abbreviations}

SERS: surface enhanced Raman spectroscopy; XRF: x-ray fluorescence spectroscopy; FORS: fiber optic reflectance spectroscopy; Cl: Colour Index.

\section{Authors' contributions}

The prints selected for analyses were assembled and dated by HDS. XRF, Raman SERS and FORS data was collected by YL and AC. AC prepared the manuscript. HDS and ML revised it. All authors read and approved the final manuscript.

\section{Author details}

${ }^{1}$ Department of Scientific Research, The Metropolitan Museum of Art, 1000 Fifth Avenue, New York, NY 10028, USA. ${ }^{2}$ School of History and Culture, Center for Archaeological Science, Sichuan University, 29 Wangjiang Road, Chengdu 610064, Sichuan, People's Republic of China. ${ }^{3}$ Department of East Asian Languages and Cultures, Columbia University, 420 West 118th Street, New York, NY 10027, USA.

\section{Acknowledgements}

The authors thank John Carpenter and Jennifer Perry (Metropolitan Museum of Art) for providing access to the MMA collection of Meiji Japanese prints.

\section{Funding}

AC is indebted to the Andrew W. Mellon Foundation for an Andrew W. Mellon fellowship in Conservation Science. YL was supported by the Advanced Interdisciplinary Innovation Project of Sichuan University (skqy201216) to conduct a period as visiting scholar at the Metropolitan Museum of Art.

\section{Publisher's Note}

Springer Nature remains neutral with regard to jurisdictional claims in published maps and institutional affiliations.

Received: 9 January 2018 Accepted: 22 March 2018

Published online: 03 April 2018

\section{References}

1. Merritt H. Woodblock prints of the Meiji Era. In: Newland AR, editor. The Hotei encyclopedia of Japanese woodblock prints. Amsterdam: Hotei Publishing; 2005. p. 230-60.

2. Tanabe M. Ukiyo-e hanga no iro: Nishiki-e ni miru Edo-gonomi no shikisai" (The colors of ukiyo-e prints: Edo-style colors as seen in nishiki-ie. In: Meguro Museum of Art, Meguro-ku Bijutsukan, Iro no hakubutsushi: Edo no shikisai o yomu, miru (The natural history of color: Reading and seeing the colors of Edo). Tokyo: Meguro-ku Bijutsukan; 2016. p. 121-5.

3. Meech-Pekarik J. The world of the Meiji print: impressions of a new civilization. New York: Weatherhill; 1986.

4. Leona M. Microanalysis of organic pigments and glazes in polychrome works of art by surface-enhanced resonance Raman scattering. Proc Natl Acad Sci. 2009;106(35):14757-62.

5. Mantler M, Schreiner M. X-ray fluorescence spectrometry in art and archaeology. X-Ray Spectrom. 2000;29(1):3-17.

6. Burgio L, Clark RJ. Library of FT-Raman spectra of pigments, minerals, pigment media and varnishes, and supplement to existing library of Raman spectra of pigments with visible excitation. Spectrochim Acta Part A Mol Biomol Spectrosc. 2001;57(7):1491-521.

7. Dupuis G, Elias M, Simonot L. Pigment identification by fiber-optics diffuse reflectance spectroscopy. Appl Spectrosc. 2002;56(10):1329-36.

8. Casadio F, Leona M, Lombardi JR, Van Duyne R. Identification of organic colorants in fibers, paints, and glazes by surface enhanced Raman spectroscopy. Acc Chem Res. 2010;43(6):782-91.

9. Luo Y, Basso E, Smith HD, Leona M. Synthetic arsenic sulfides in Japanese prints of the Meiji period. Herit Sci. 2016;4(1):17.

10. Yamato A. Kôki ukiyo-e hanga ni shiyô sareta shikizai no hensen ni kansuru kenkyû (Studies on changes in the colorants used in later ukiyo-e prints. Master Thesis. Tohoku University of Art and Design, Japan; 2013.

11. Rowe M, editor. Colour index. Bradford: The Society of Dyers and Colourists; 1924.

12. Travis AS. The rainbow makers: the origins of the synthetic dyestuffs industry in Western Europe. London: Associated University Presses; 1993.

13. Horobin RW, Kiernan JA, editors. Conn's biological stains: a hanbook of dyes, stains and fluorochromes for use in biology and medicine. Oxford: BIOS Scientific Publisher Ltd; 2002.

14. Cesaratto A, Lombardi JR, Leona M. Tracking photo-degradation of triarylmethane dyes with surface-enhanced Raman spectroscopy. J Raman Spectrosc. 2017:48(3):418-24.

15. Geiman I, Leona M, Lombardi JR. Application of Raman spectroscopy and surface-enhanced raman scattering to the analysis of synthetic dyes found in ballpoint pen inks. J Forensic Sci. 2009;54(4):947-52.

16. Confortin D, Neevel H, Brustolon M, Franco L, Kettelarij AJ, Williams RM, van Bommel MR. Crystal violet: study of the photo-fading of an early synthetic dye in aqueous solution and on paper with HPLC-PDA, LC-MS and FORS. J Phys Conf Ser. 2010;231:012011.

17. Favaro G, Confortin D, Pastore P, Brustolon M. Application of LC-MS and LC-MS-MS to the analysis of photo-decomposed crystal violet in the investigation of cultural heritage materials aging. J Mass Spectrom. 2012;47:1660-70

18. Feller RL, Curran M, Bailie C. Identification of traditional organic colorants employed in Japanese prints and determination of their rates of fading. In: Japanese woodblock prints. A catalogue of the Mary A. Ainsworth collection. Oberlin. 1984. p. 253-64.

19. Connors SA, Whitmore PM, Keyes RS, Coombs El. The identification and light sensitivity of japanese woodblock print colorants: the impact on art history and preservation. In: Scientific research on the pictorial art of Asia. Proceedings of the second Forbes symposium at the freer gallery of art. 2005. p. 35-47.

20. Fitzhugh EW. A database of pigments on Japanese Ukiyo-e paintings in the Freer Gallery of Art. In: Fitzhugh E, Winter J, Leona M, editors. Pigments in later japanese paintings. Washington DC: Freer Gallery Occasional Papers; 2003. p. 1-41.

21. Schweppe $H$, Roosen-Runge $H$. Carmine-cochineal carmine and kermes carmine. In: Feller L, editor. Artists' pigments. A handbook of their history and characteristics, vol. 1. New York: Cambridge University Press; 1986. p. 255-84.

22. Donkin RA. The insect dyes of Western and West-Central Asia. Arthropos. 1977;72:847-80.

23. Peck A, Bogansky AE. Interwoven globe: the worldwide textile trade, 1500-1800. Metropolitan Museum of Art: New York; 2013.

24. Bethe M, Sasaki Y. Reds in the land of the rising sun. Cochineal and traditional red dyes in Japan. In: Padilla C, Anderson B, editors. A red like no other: how cochineal colored the World. Skira Rizzoli: New York; 2015. p. $76-81$.

25. Konta S. Mogami benibana shi no kenkyû (Studies in the history of Mogami safflower). Yamagata: Kōyōdō Shoten; 1979.

26. Sánchez MR. Historial del cultivo de la grana o cochinilla en Guatemala. Guatemala: Tipografía Nacional; 1994.

27. Brown AS. Madeira and the Canary Islands: a practical and complete guide. London: Sampson Low, Marston \& Co; 1898.

28. Leona M, Winter J. Fiber optics reflectance spectroscopy: a unique tool for the investigation of Japanese paintings. Stud Conserv. 2001;46:153-62.

29. Greeneltch NG, Davis AS, Valley NA, Casadio F, Schatz GC, Van Duyne RP, Shah NC. Near-infrared surface-enhanced raman spectroscopy (NIR-SERS) for the identification of eosin Y: theoretical calculations and evaluation of two different nanoplasmonic substrates. J Phys Chem A. 2012;116(48):11863-9. 
30. Gettens RJ, Stout GL. Painting materials: a short encyclopaedia. New York: Dover Publications Inc; 1966.

31. Richmond WD. Colour and colour printing, as applied to Lithography. 3rd ed. E. Menken: London; 1985.

32. Mitchell CA, Hepworth T. Inks: their composition and manufacture; including methods of examination and full list of patents. London: Charles Griffin \& Company; 1916.

33. Cesaratto A, Centeno SA, Lombardi JR, Shibayama N, Leona M. A complete Raman study of common acid red dyes: application to the identification of artistic materials in polychrome prints. J Raman Spectrosc. 2017:48(4):601-9.

34. Azuma nishiki-e no suisei wo bankai sen to su (Trying to Reverse the Decline of Azuma Nishiki-e). In:Yomiuri Shimbun Newspaper. Aug-1890.

35. Koizumi E. Jitsuyō shikiso shinsetsu (A new theory of practical colorants). Eirandō: Tokyo; 1894.

36. Antreasian GZ, Adams C. Lithographic inks. In: The Tamarind book of lithography: art and techniques. New York: Harry N. Abrams, Inc; 1971. p. 301-19.
37. Centeno SA, Lladó Buisan V, Ropret P. Raman study of synthetic organic pigments and dyes in early lithographic inks (1890-1920). J Raman Spectrosc. 2006;37:1111-8.

38. Casadio F, Mauck K, Chefitz M, Freeman R. Direct identification of early synthetic dyes: FT-Raman study of the illustrated broadside prints of José Gaudalupe Posada (1852-1913). Appl Phys. 2010;100:885-99.

39. Twyman M. A history of chromolithography: printed colour for all. New Castle: Oak Knoll Press; 2013.

40. Gotō S. Nihon senshoku fu (Album of weaving and dyeing in Japan). Tokyo; 1964.

41. Ōsaka Enogu Senryō Dōgyō Kumiai: Enogu senryō shōkō shi (History of trade and manufacture of pigments and dyes). Osaka; 1938.

42. Smith HD. Hokusai and the Blue Revolution in Edo Prints. In: Carpenter JT, editor. Hokusai and his age: ukiyo-e painting, printmaking, and book illustration in late Edo Japan. Amsterdam: Hotei Publishing; 2005. p. 234-69.

\section{Submit your manuscript to a SpringerOpen ${ }^{\circ}$ journal and benefit from:}

- Convenient online submission

- Rigorous peer review

- Open access: articles freely available online

- High visibility within the field

- Retaining the copyright to your article

Submit your next manuscript at $\boldsymbol{\nabla}$ springeropen.com 